\title{
ATIVIDADE LÚDICA DESENVOLVIDA PARA FACILITAR O ENTENDIMENTO DE COMO SURGEM OS MODELOS
}

\section{J. R. C. Rocha}

Faculdade Estadual de Filosofia Ciências e Letras de Paranaguá - FAFIPAR - Universidade Estadual do Paraná

(UNESPAR) - Campus Paranaguá

jrcaetanorocha@ig.com.br

Artigo submetido em novembro/2012 e aceito em dezembro/2012

\section{RESUMO}

Nesse trabalho relata-se o procedimento pedagógico alternativo aplicado para turmas de primeira série do ensino médio da E. E. Fernão Dias Paes e da E. E. Anhanguera, ambas localizadas na capital Paulista, Brasil. Esse procedimento foi baseado em relatos de atividades produzidas nos anos 60 e 70, onde eram introduzidos diferentes objetos em recipientes lacrados e as pessoas tinham que identificar qual objeto foi ali acondicionado sem que pudessem abrir os recipientes. O objetivo principal do procedimento pedagógico era que esses alunos compreendessem como surgem às teorias, as leis, as hipóteses e os modelos. Aqui também são apresentados alguns dos resultados obtidos durante a transformação de conhecimentos comuns que os alunos adquiriram no seu cotidiano em conhecimentos científicos. Esse fato acontece devido a alguns dos obstáculos epistemológicos serem eliminados e os alunos conseguirem obter razões suficientes para substituir o conhecimento anterior e desta forma promover sua aprendizagem.

PALAVRAS-CHAVE: Ensino de Química, atividade lúdica, desenvolvimento de modelos.

\section{LUDIC ACTIVITY DEVELOP TO FACILITATE THE UNDERSTANDING OF HOW MODELS APPEAR} \section{ABSTRACT}

In this paper we report the alternative pedagogical procedure applied to classes of first grade of high school E. E. Fernão Dias Paes and E. E. Anhanguera, both located in the capital São Paulo, Brazil. This pedagogical procedure was based on reports of activities produced in the 60 and 70 , where different objects were placed in sealed receptacle and people had to identify which object was put there so people could not open the receptacle. The main objective of the procedure was that these students come to understand how theories, laws, hypotheses and models. Here also are some of the results obtained during the processing of common knowledge that students acquired in their daily scientific knowledge. This fact is due to some of the epistemological obstacles could be eliminated and students fail to obtain sufficient reason to replace the prior knowledge and thus promoting their learning.

KEY-WORDS: chemistry teaching, ludic activity, models development. 


\section{ATIVIDADE LÚDICA DESENVOLVIDA PARA FACILITAR O ENTENDIMENTO DE COMO SURGEM OS MODELOS}

\section{INTRODUÇÃO}

Na literatura existem vários textos que comentam sobre a dificuldade de alunos do ensino médio de apropriar-se de conteúdos da disciplina química. Nestes textos se relaciona as dificuldades dos alunos em assimilar os conteúdos científicos devido aos conceitos prévios que estes adquiriram no seu cotidiano. Entre os conteúdos discutidos por esses autores está a representação simbólica e molecular da química (WU; KRAJCIK; SOLOWAY, 2001); a eletronegatividade, as ligações químicas, a geometria molecular e a representação microscópica (NICOLL, 2001); as dificuldades de assimilação de conceitos estequiométricos (FACH; BOER; PARCHMANN, 2007); a visualização de uma reação química por parte dos alunos (BEN-ZVI; EYLON; SILBERSTEIN, 1987); a dificuldade dos estudantes de não entenderem algumas das idéias fundamentais que formam a base da disciplina química (GABEL; SAMUEL; HUNN, 1987). Em todos estes textos se verifica que erros conceituais e as dificuldades em absorver os conceitos relacionados às mudanças físicas e químicas nos três níveis (macroscópico, microscópico e simbólico) - que os químicos em geral utilizam para descrever os fenômenos químicos - são extremamente comuns.

Os conteúdos programáticos aplicados nas primeiras séries do ensino médio e relacionados com a estrutura atômica e atrações moleculares são extremamente abstratos, desta forma, para que os alunos do ensino médio entendam estes conteúdos eles devem se familiarizar com alguns conceitos matemáticos e físicos, além de posteriormente associá-los a outros conteúdos, como: forças intermoleculares, orbitais, eletronegatividade, polaridade, entre outros (NAHUM; MAMLOK-NAAMAN; HOFSTEIN; KRAJCIK, 2007).

Em 1988, Ben-Zvi et al., explicita que a química é considerada, por muitos alunos do ensino médio, como uma das disciplinas mais difíceis de ser assimilada. Embora esclareça que muito se tem falado acerca da natural abstração dos conceitos químicos e da incapacidade dos alunos de atingir a fase operatório-formal, continua-se a "forçar" alunos que não atingiram essa fase cognitiva a abstrair e realizar tarefas que eles não conseguem compreender. Como fazer com que alunos que estão na fase operatório-concreta deixem que seu pensamento se torne livre das limitações da realidade concreta? Segundo Piaget é necessário que primeiro esse aluno atinja essa fase, para que depois ele consiga pensar de modo lógico e correto mesmo com algo incompatível com o real, conseguindo pensar e trabalhar não só com a realidade concentra, mas também com a realidade possível. Dessa forma ele consegue produzir e operar com base em hipóteses, visto que estas não são, em princípio, nem verdadeiras nem falsas - são apenas possibilidades - derivando delas todas as conseqüências lógicas cabíveis (PIAGET, 1978).

Pensando assim acredita-se que os alunos do ensino médio não conseguem assimilar ou compreender estes conceitos fundamentais de química, principalmente por que eles não compreendem como estes conceitos surgiram. Tentar explicar a partir de aulas teóricas qualquer um desses conceitos se torna impraticável porque eles terão uma visão muito restrita sobre este conteúdo e continuarão a ter as mesmas dúvidas sobre outros conteúdos. Tentar explicar a partir de aulas práticas de laboratório é extremamente complicado, visto que o experimento deveria trabalhar o lado microscópico e novamente os alunos de ensino médio não teriam elementos para o entendimento específico. Além do que, para que muitos 
destes conceitos fossem observados em uma aula experimental as escolas deveriam ter equipamentos mais sofisticados e os professores deveriam ser capacitados para utilizá-los e transmitir estes conceitos.

Outro fato importante diz respeito às concepções prévias que os alunos apresentam quando chegam à primeira série do ensino médio. Muitas vezes se percebe, durante essas aulas, que estas concepções estão centradas em fatos místicos e/ou fantasiosos. Estes fatos fazem com que os alunos não consigam, utilizando-se de uma aula discursiva, ou utilizando-se de uma aula dialogada ou ainda de uma aula experimental, eliminar certos obstáculos epistemológicos. Para que isso aconteça se torna necessário realizar atividades que os auxilie na eliminação destes obstáculos.

As ideias de Bachelard (LOPES, 2007) são claras quando indica que a ciência não é uma atividade simples e que não pode ser simplificada a qualquer custo sem que ela seja negada. Bachelard (LOPES, 2007) ainda indica que nas primeiras lições se tem o direito de ser incompleto ou esquemático, porém nunca se pode ser falso nos conceitos que são transmitidos. Subentende-se aqui que as primeiras lições da disciplina química acontecem no final do ensino fundamental e durante o ensino médio, portanto nesse momento é possível apresentar a ciência química esquematicamente ou mesmo de forma incompleta usando atividades que chamem a atenção do aluno. Ir construindo o conhecimento desses alunos aos poucos e em solo seguro onde os conceitos iniciais foram compreendidos e sedimentados é essencial, e acima de tudo relacionar o conteúdo programático com a atividade apresentada. Além do que desenvolver atividades que privilegie esta fase de transição cognitiva entre o operatório-concreto e o operatório formal, apresentando modelos concretos - mesmo que sejam macroscópicos para depois relacionar com o microscópico - que auxiliem esses alunos a visualizar os conceitos desejados e garantindo a abstração necessária.

As atividades lúdicas são técnicas usadas para construir, reconhecer ou definir conceitos, pois estas atividades são muito fáceis de serem desenvolvidas e tanto as crianças como os adultos reconhecem estas idéias com um nível de dificuldade muito baixo (PELLEGRINI, 2003). Os jogos ou atividades lúdicas são importantes na escola, mas antes disso são importantes para a vida. Se no interior das escolas as atividades lúdicas fossem aplicadas com maior ênfase a possibilidade dos alunos aprenderem seria, talvez, bem maior (MACEDO, 1995). Rocha e Cavichiolli (2005) verificaram que os alunos de turmas de ensino médio assimilavam de forma mais consistente os conteúdos apresentados utilizando anteriormente uma atividade lúdica específica para aquele conteúdo programático. Por este motivo o interesse de desenvolver novas atividades alternativas que auxiliem de forma motivadora os alunos do ensino médio no processo ensino-aprendizagem.

A dificuldade dos alunos de ensino médio em absorver como os modelos foram desenvolvidos, seja na disciplina química ou em outras ciências, reside no fato de que os mesmos não conseguem perceber que o conhecimento científico está centrado no acúmulo e no registro de informações que são aceitas pela comunidade cientifica. A maioria destes alunos tem como conceito prévio que o desenvolvimento científico acontece graças a um único cientista. Para esses alunos o cientista em evidência é mais inteligente do que outras pessoas. Com a atividade lúdica proposta pretende-se que esse pré-conceito seja alterado. Avaliando o que foi descrito anteriormente, os principais objetivos desse trabalho são o de produzir atividades alternativas, visto que as mesmas são motivadoras no processo ensinoaprendizagem. Além de promover a mudança conceitual de que os avanços tecnológicos e 
conceituais das ciências ocorrem pelo acumulo de informações cientificas e não pela genialidade de um cientista.

\section{METODOLOGIA}

Essa atividade pedagógica alternativa foi realizada em duas etapas. Na primeira etapa ocorreu uma avaliação diagnóstica, onde se verificou os conhecimentos prévios que os alunos de turmas da primeira série do ensino médio apresentam ao ingressarem na referida turma. Na segunda etapa aplicou-se a atividade lúdica aqui proposta e que foi baseada em relatos de jogos e brincadeiras que eram realizados nos anos 60 e 70. Nesses jogos eram introduzidos diferentes objetos em caixas que eram lacradas em seguida, e os participantes dos jogos tinham que descobrir qual objeto foi ali acondicionado, sem que esses participantes pudessem abrir as caixas.

\section{a) Avaliação Diagnóstica}

No início do período letivo foram realizadas avaliações diagnósticas em cada uma das turmas de primeira série do ensino médio para determinar os conhecimentos prévios que esses alunos tinham sobre três tópicos essenciais: (a) O que é e por que estudar química? (b) Como acontecem às novas descobertas? (c) Como os cientistas desenvolvem novas teorias?

Para a realização da atividade, a lousa foi dividida em três partes, onde foram registradas as perguntas e abaixo de cada uma delas foram registradas as respostas obtidas referentes a cada uma das questões. Para centralizar a linha de raciocínio dos alunos a questão (b) somente foi escrita na lousa após não existirem mais respostas para a questão (a). Por sua vez a questão (c) somente foi escrita na lousa após não existirem respostas para a questão (b).

Quando a resposta dos alunos foi considerada dúbia se realizou intervenções para melhor entender o pensamento deste aluno, sendo que essas intervenções estão registradas entre parênteses, no texto abaixo. Na maioria das respostas obtidas das três questões propostas durante a avaliação diagnóstica se percebeu vários conceitos prévios distorcidos e/ou fantasiosos desses alunos. Alguns destes exemplos são apresentados abaixo:

- A Química é muito difícil.

- A Química é muito ruim. (Por quê?) - Porque ela suja os rios e o meio ambiente.

- Nós não precisamos estudar Química! (Por quê?) - Por que não serve para nada. A Química destrói a natureza.

- Porque nascem pessoas inteligentes e elas descobrem novas coisas que são boas pra gente. Às vezes as coisas não são boas e muita gente morre.

- Algumas pessoas ficam pensando a vida toda até que aparece uma grande idéia. (Como assim?) - Ué! A pessoa pensa, pensa, pensa, daí alguém fala como as coisas são. (Alguém! Quem é este alguém?) - Um ser de outro planeta. Um fantasma. (Fantasma! Que fantasma?) - Ah! Não sei. Só um fantasma. 
Poucas ou quase nenhuma das respostas proferidas pelos alunos denotavam relação com o acúmulo e aperfeiçoamento das informações disseminadas pela comunidade científica. Um dos poucos exemplos é citado abaixo:

- A Química estuda as coisas que estão a nossa volta. (Como assim?) As pedras, os carros, avião, navio. Ela vê do que cada coisa é feita.

Na segunda parte dessa aula diagnóstica foi discutida cada uma das respostas apresentadas pelos alunos sobre as três questões que foram propostas inicialmente, tentando assim minimizar os pontos negativos apresentados pelos alunos em seus conceitos prévios e iniciando a mudança dos conceitos prévios por conceitos científicos.

Durante as três semanas seguintes as aulas apresentadas para essas turmas foram sobre conceitos referentes à ciência Química e a diferenciação entre processos químicos e processos físicos, ou seja, se trabalhou de forma contextualizada com a parte macroscópica dessa ciência. Dessa forma foram abordados os conceitos referentes às transformações químicas que são comentadas nos PCN's (BRASIL, 1996) e que posteriormente são listadas nas "Orientações Curriculares para o Ensino Médio" do Ministério da Educação (BRASIL, 2006).

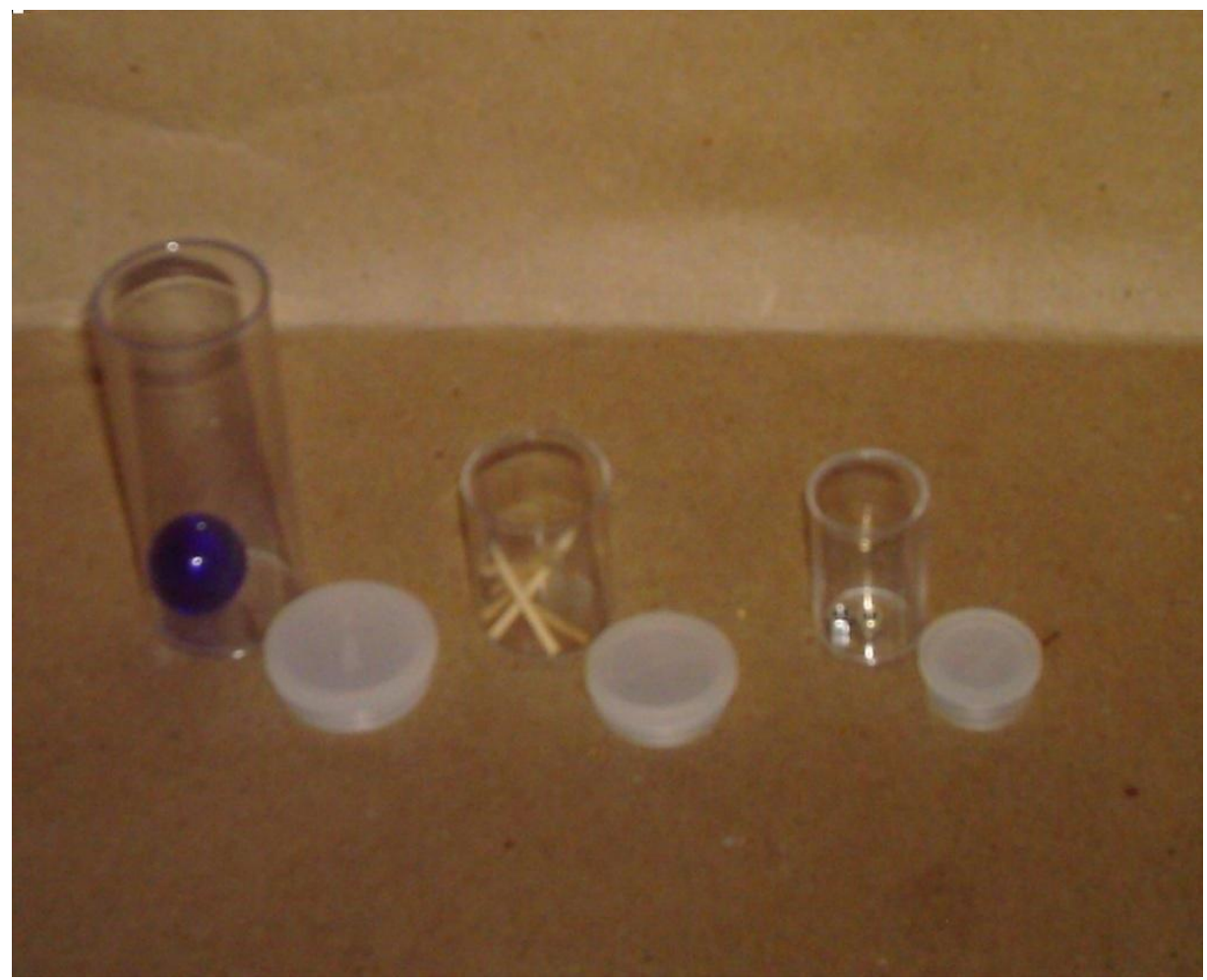

Figura 1 - Imagem das embalagens plásticas e dos objetos utilizados nesta atividade pedagógica alternativa.

\section{b) Procedimento da Atividade Lúdica}

Antecipadamente foram preparados dez conjuntos de três embalagens lacradas que foram entregues para cada um dos grupos de alunos para realizar a atividade pedagógica 
alternativa. Para preparar esses conjuntos foram usadas embalagens plásticas de três tamanhos diferentes. Em cada uma das embalagens plástica de tamanho maior foi colocada uma bolinha de gude de vidro. Nas embalagens plásticas de tamanho médio foram colocados palitos de dentes quebrados, pois como à altura da embalagem não comportava os palitos inteiros, os mesmos foram quebrados ao meio e acondicionados em cada uma dessas embalagens. Já em cada uma das embalagens plástica de tamanho menor foram colocadas duas porcas metálicas, conforme imagem apresentada na Figura 1.

Após colocar os objetos no interior de cada uma das embalagens as mesmas foram fechadas e envoltas com folhas de papel sufite para dificultar a visão do objeto posicionado no interior de cada uma das embalagens. Por fim a embalagem foi lacrada utilizando diversas camadas de fita crepe, como pode ser observado na Figura 2

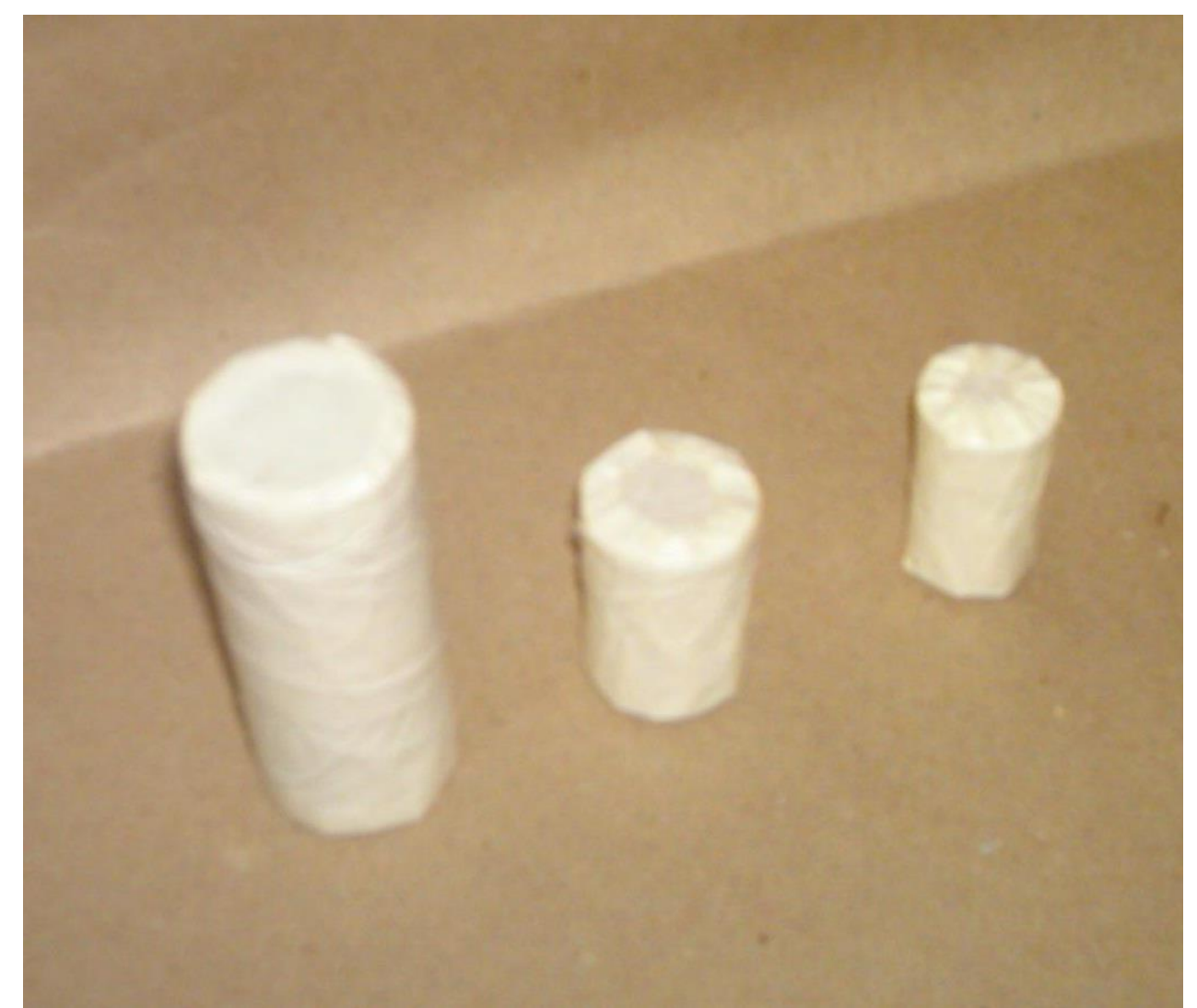

Figura 2 - Imagem das embalagens plásticas que são entregues aos alunos para que os mesmos descubram o seu conteúdo, após as mesmas serem montadas e envolvidas com fita crepe.

No início dessa aula os alunos foram informados que os mesmos realizariam uma atividade em grupo e cada um desses grupos seria formado por quatro componentes. Em seguida foram estabelecidas as regras e as informações gerais da atividade:

(1) cada grupo receberia um conjunto de três embalagens lacradas;

(2) as embalagens de mesmo tamanho teriam os mesmos objetos;

(3) o tempo para que os grupos determinassem qual o objeto que está no interior de cada uma das embalagens foi de dez minutos; 
(4) eles poderiam realizar qualquer experimento possivel com as embalagens;

(5) o único teste que não poderiam realizar era abrir as embalagens, pois essa seria a única regra da atividade "AS EMBALAGENS NÃO PODERÃO SER ABERTAS".

Por fim se desenhou na lousa a tabela utilizada para registrar as informações fornecidas pelos alunos durante a realização da atividade (Tabela 1).

Tabela 1 - Tabela utilizada para registrar as informações fornecidas pelos alunos após os mesmos realizarem os testes nas embalagens plásticas.

\begin{tabular}{c|c|c}
\hline & $\begin{array}{c}\text { Qual é o objeto que existe em } \\
\text { cada uma das embalagens? }\end{array}$ & $\begin{array}{c}\text { Como vocês chegaram } \\
\text { a está hipótese? }\end{array}$ \\
\hline $\begin{array}{c}\text { Embalagem } \\
\text { Grande }\end{array}$ & & \\
\hline $\begin{array}{c}\text { Embalagem } \\
\text { Média }\end{array}$ & & \\
\hline $\begin{array}{c}\text { Embalagem } \\
\text { Pequena }\end{array}$ & & \\
\hline
\end{tabular}

Após o tempo estipulado para que cada um dos grupos determinasse qual era o objeto que estava no seu interior, aleatoriamente, pediu-se que cada grupo informasse o conteúdo da embalagem grande, sendo que essas informações foram anotadas na tabela desenhada na lousa. Em seguida cada um dos grupos informou, também aleatoriamente, como eles chegaram à hipótese de que era aquele o objeto que estava no interior da embalagem grande. O mesmo procedimento foi realizado para obter as informações sobre o conteúdo da embalagem média e da embalagem pequena.

Como fechamento dessa aula se discutiu as diferentes hipóteses lançadas pelos grupos a respeito do conteúdo de cada uma das embalagens. Comentou-se que os modelos propostos por eles foram desenvolvidos usando os conceitos prévios que eles tinham em relação às propriedades e características da matéria, visto que embora eles não soubessem qual era o conteúdo da embalagem, eles propuseram uma hipótese e por sua vez lançaram um modelo mental.

Comentou-se ainda, que os modelos e as hipóteses que foram e são lançadas por pesquisadores - de diferentes áreas do conhecimento - acontecem de forma similar, respeitando as devidas proporções, ao que ocorreu durante a atividade, ou seja, os cientistas utilizando-se de conceitos que são aceitos pela comunidade científica da época que vive, lançam hipóteses para explicar fatos que ainda não são explicáveis até aquele momento 
histórico. Caso a hipótese ou o modelo lançado explica ou ainda demonstra de forma convincente aquilo que não podia ser explicado até aquele momento, então a comunidade científica aceita a hipótese ou o modelo apresentado.

Para as turmas em que foi aplicada esta atividade se optou em informar o conteúdo da embalagem plástica grande e comentar que os objetos que estão nas outras embalagens (média e pequena) são de tamanho menor do que a bolinha de gude. Este fato tornou-se necessário por que os alunos ficaram muito curiosos sobre os conteúdos das embalagens. Para eles era muito importante saber se tinham acertado ou não o objeto que estava no interior da embalagem plástica e por sua vez verificar se a hipótese lançada por eles era correta ou não.

Preferiu-se, nesse momento, não comentar o conteúdo das outras embalagens, indicando que muitos modelos e hipóteses que são propostas pelos cientistas também são descartadas após certo período de tempo devido a avanços tecnológicos ou ainda devido a mudanças de idéias políticas, religiosas, sociais ou econômicas da sociedade pensante da época. Como exemplo foi citado à mudança conceitual em relação ao modelo geocêntrico onde os cientistas dessa época acreditavam que a Terra era o centro do universo. Posteriormente Copérnico propôs o modelo heliocêntrico que indicava que o Sol era o centro do universo. Hoje, a partir da teoria da relatividade, se entende que não existe uma região privilegiada do espaço, principalmente assumindo a idéia de que o universo não é limitado.

Essa prática pedagógica foi adotada em anos posteriores, onde se percebeu que os alunos chegavam ao ensino médio com os mesmos conhecimentos comuns, ou seja, estes novos alunos apresentavam respostas similares àquelas obtidas no período letivo anterior. Acreditase que, em sala de aula, esse tipo de atividade pedagógica alternativa auxilia na incorporação de conceitos científicos de forma lúdica e auxilia ainda na motivação do processo ensinoaprendizagem.

\section{RESULTADOS E DISCUSSÃO}

Os resultados apresentados a seguir são qualitativos e não quantitativos, visto que, o objetivo principal da atividade pedagógica foi para que os alunos de ensino básico conseguissem entender como surgem às hipóteses e por sua vez os modelos utilizados para justificar essas hipóteses. E não quantos alunos acertam ou erram o objeto que se encontrava no interior de cada uma das embalagens plásticas utilizadas.

As hipóteses que os alunos, das diferentes turmas, apresentaram para indicar o objeto que foi colocado no interior da embalagem grande são apresentadas na Tabela 2. Algumas dessas hipóteses foram indicadas em maior proporção e outras em menor proporção.

Tabela 2 - Hipóteses que os alunos indicaram sobre o objeto colocado no interior da embalagem plástica grande.

Bolinha de gude;

Pedras;

Bolinha de chumbo; 


\begin{tabular}{l|l|l}
\hline Bolinha de ferro; & Moeda; & Bolinha de rolimã; \\
\hline Chumbo; & Pilha Palito; & Bolinhas de gude. \\
\hline
\end{tabular}

Para fundamentar essas hipóteses foram lançadas algumas explicações, e as mesmas são apresentadas a seguir, sendo que algumas dessas explicações foram apresentadas por mais de um grupo, já outras explicações foram emitidas por apenas um dos grupos.

- Movimento circular, peso, gravidade, som, contra a luz apresentava o formato de bola, som de bola de vidro batendo, deslizando, peso de bolinha, tamanho, movimento dos objetos, movimento;

- Pelo movimento não circular;

- Aparência retangular.

Analisando as justificativas é possível perceber que alguns alunos apresentam dúvidas em relação ao que seja o movimento circular. Esses alunos não conseguem visualizar que um objeto que faz movimento contínuo sobre uma superfície lisa apresenta características de um objeto circular, principalmente quando esse objeto está em contato direto e contínuo sobre essa superfície, ou seja, em nenhum momento o objeto perde o contato com a superfície lisa.

Novamente, ao avaliar a linguagem dos alunos se percebeu vários conceitos prévios distorcidos e/ou fantasiosos, e é perceptível a confusão que alguns fazem em relação a alguns conceitos científicos. Verifica-se ainda que esses alunos manifestam a idéia de que os termos massa, peso e gravidade são sinônimos, ou seja, que os mesmos apresentam o mesmo significado conceitual. Além de diferenciar a constituição da matéria pelo peso do objeto, indicando que o objeto é de ferro, de chumbo ou de vidro unicamente avaliando o peso que o objeto apresenta.

Também foi possível perceber que alguns alunos do grupo em estudo apresentaram linha de raciocínio diferenciada da maioria dos alunos observados. Enquanto a maioria dos componentes dos diferentes grupos observava o peso, o movimento e o som que o objeto fazia no interior da embalagem, alguns alunos se dirigiram até a janela e colocaram as embalagens contra a luz tentando assim visualizar o perfil do objeto acondicionado no interior da embalagem plástica contra uma fonte luminosa. $O$ fato mais importante relacionado a essa atitude é que o aprendizado pode ser copiado ou imitado e desta forma interiorizado por outros alunos. Após verificarem a atitude desses alunos, outros seguiram o exemplo e também foram até a janela para observar as embalagens contra a luz.

Posteriormente, os alunos, das diferentes turmas observadas naquele ano letivo, lançaram hipóteses sobre o conteúdo da embalagem plástica média, e algumas dessas hipóteses são apresentadas na Tabela 3.

Tabela 3 - Hipóteses que os alunos indicaram sobre o objeto colocado no interior da embalagem plástica média. 


\begin{tabular}{c|c|c}
\hline Arroz; & Palito de dente; & Grão de Arroz; \\
\hline Grafite; & Miçangas; & Sementes; \\
\hline $\begin{array}{c}\text { Palito de dente ou } \\
\text { grafite; }\end{array}$ & $\begin{array}{c}\text { Palito de fósforo ou palito } \\
\text { de dente quebrado; }\end{array}$ & $\begin{array}{c}\text { Palito de dente } \\
\text { cortado; }\end{array}$ \\
\hline Palito de fósforo; & Grãos ou sementes, & Pedrinhas. \\
\hline
\end{tabular}

Para fundamentar as suas hipóteses estes mesmos alunos apresentaram algumas justificativas de como eles chegaram à conclusão sobre o conteúdo da embalagem plástica média, e esses resultados são apresentados abaixo:

- Peso (leve); contra a luz se percebe o formato pontiagudo; som; só faz um movimento; leve; quantidade maior; leveza; quando movimenta apresenta som baixo durante a queda; contra a luz a cor e o formato de palito de dente cortado; peso muito leve; tipo um instrumento musical indígena (chocalho); som de madeira batendo; formato comprido como de palitos de fósforo; formato longo e pontiagudo como de grafite; movimento leve e solto da parede (interna); som de miçangas batendo; som de arroz chacoalhando; som de pedrinhas se chocando.

Nessa segunda série de hipóteses e justificativas lançadas para indicar qual seria o objeto que se encontra no interior da embalagem plástica média se percebe que os alunos apresentaram maior dificuldade em desenvolver o seu modelo. Provavelmente este fato esteja relacionado com as características e propriedades que os alunos normalmente avaliam dos objetos posicionados no interior da embalagem, tais como o peso, o som e o movimento. Como o conteúdo dessa embalagem era leve e o som provocado no interior da embalagem era abafado tornando mais difícil a avaliação.

Obviamente se percebe pelas justificativas indicadas, que os alunos tentaram verificar o perfil do objeto contra uma fonte luminosa, mas nesse caso específico o perfil observado poderia ser de diferentes tipos de objetos, confundindo assim o modelo definido por eles.

Por fim na Tabela 4, exibida abaixo, são apresentadas as hipóteses referentes ao conteúdo observado na embalagem plástica pequena pelos alunos das diferentes turmas desse período letivo.

Tabela 4 - Hipóteses que os alunos indicaram sobre o objeto colocado no interior da embalagem plástica pequena.

\begin{tabular}{c|c|c}
\hline Pedrinha; & Chaves de diário; & Moedas; \\
\hline Porca + roela; & Porcas ou guizos. & Feijão; \\
\hline Pedra pequena; & Bolinha de chumbo; & Pedra; \\
\hline
\end{tabular}




\begin{tabular}{c|c|c}
\hline Botão metálico; & Sininhos de chaveiro; & Bolinhas; \\
\hline Pedra de chumbo; & $\begin{array}{c}\text { Bolinha de plástico com outro } \\
\text { objeto dentro; }\end{array}$ & Dado; \\
\hline Bolinha de vidro; & Pedaço de metal. & \\
\hline
\end{tabular}

Para justificarem suas hipóteses sobre o conteúdo da embalagem plástica pequena, os alunos dos grupos das diferentes turmas, comentaram:

- Barulho, barulho e peso, peso e som, pelo barulho, , som e movimento, movimento em pé e deitado, som metálico, formato, som de queda, som quantidade e tamanho, som, peso, quantidade, formato esférico, som (barulho), leveza, som de pedra chocando, movimento não circular, movimento peça achatada, som de pedra batendo no plástico, solta, som de pedra batendo em outra pedra, aparentemente pedra pequena.

O processo de aplicação desse procedimento pedagógico alternativo foi realizado em algumas etapas. Na primeira parte da aula os alunos ficavam envolvidos em descobrir o objeto que foi colocado no interior de cada uma das embalagens plásticas. Os alunos demonstravam interesse em realizar a atividade, visto que os mesmos discutiam e expunham suas hipóteses e idéias com os outros membros do grupo e desta forma a aula transcorria de forma descontraída. Professores do ensino básico que introduzem o lúdico em sala de aula percebem que a maioria dos alunos - para não indicar a totalidade - fica mais motivada para o aprendizado. Assim, os alunos conseguem assimilar os conteúdos trabalhados sempre de uma forma mais fácil e eficiente. Esta é uma das oportunidades para diversificar a atividade didática, o que na nossa experiência é fundamental para um maior envolvimento dos alunos no processo ensino-aprendizagem (ROCHA; CAVICHIOLI, 2005).

Na parte da aula em que os alunos apresentam e justificavam suas hipóteses sobre o conteúdo de cada uma das embalagens plástica se percebe a influência das concepções prévias. Discutiu-se ainda sobre a dificuldade que eles (alunos) tiveram para apresentar hipóteses sobre os objetos de menor tamanho. A quantidade de hipóteses lançadas sobre os objetos de menor tamanho ou peso que foram colocados no interior da embalagem plástica eram em maior número e mais diversificadas do que as hipóteses lançadas sobre o objeto maior (bolinha de gude). Neste momento se avaliou às dificuldades que os alunos tiveram para lançar hipóteses de objetos de peso e de tamanho cada vez menor.

Na parte final dessa aula foram discutidas as repostas e justificativas dos alunos sobre os conteúdos das embalagens plásticas. Nesta fase da atividade se indicou aos alunos que eles apresentaram modelos para o conteúdo de cada uma das embalagens estudadas, sendo que estes modelos foram obtidos de acordo com as propriedades e características da matéria que eles conheciam.

Como última etapa da aula, foi pedido para que os alunos pensassem sobre algumas questões que serão discutidas nas próximas aulas. (1) Com os testes que foram realizados 
hoje é possível garantir qual a composição química dos objetos que estavam no interior das embalagens plástica? Por exemplo, se a bolinha era de vidro ou de aço? (2) Caso existissem outros equipamentos para que eles realizassem as avaliações analíticas seria mais fácil o desenvolvimento de novos modelos? (3) Caso eles conhecessem mais informações sobre as propriedades e características da matéria, não seria mais fácil para identificar o conteúdo das embalagens e por sua vez lançar outro modelo diferente daquele que foi indicado anteriormente?

A discussão realizada na aula seguinte em cada uma das turmas foi extremamente importante, pois foi possível perceber que os alunos entenderam que as hipóteses, os modelos, as leis e as teorias surgem a partir do acúmulo de informações geradas por vários pesquisadores de diferentes áreas do conhecimento e que são baseadas em conceitos aceitos pela comunidade científica.

\section{CONCLUSÕES}

Atividades lúdicas atingem os objetivos pedagógicos esperados, pois além de motivar a aprendizagem do aluno traz o conceito desenvolvido para o concreto (ROCHA; CAVICHIOLLI, 2005). Elas permitem ainda que os alunos se relacionem de forma positiva com os outros membros do grupo durante e posteriormente a aplicação da atividade. Além de desenvolver nos alunos a possibilidade da abstração e também a capacidade dos mesmos de melhorarem a forma de comunicação com outras pessoas. Assim o desenvolvimento desse tipo de atividade faz com que o aluno consiga reconhecer, construir e definir a aprendizagem como algo importante para a sua vida.

Os alunos conseguiram entender principalmente como surgem às hipóteses, as teorias, as leis e os modelos. Esse fato ficou claro quando foram analisadas várias atividades e conceitos explicados posteriormente nas aulas da disciplina Química.

Percebeu-se ainda que, para esse grupo de alunos, sempre que surgia a discussão sobre um novo modelo ou teoria ou lei eles queriam saber quais eram as propriedades e as características da matéria que o cientista se baseou para lançar a mesma.

E por fim observou-se que esses alunos se tornaram mais questionadores e ávidos pelo conhecimento, quando os mesmos são comparados com alunos de turmas anteriores onde essa atividade didática não foi aplicada.

\section{AGRADECIMENTOS}

A Profa. Emilia Ribas Plaza Lisboa, ex-diretora da E. E. Fernão Dias Paes, e a Profa. Noemi Célia de S. N. Affonso, ex-diretora da E. E. Anhanguera, pela confiança que ambas demonstraram durante a realização de todos os trabalhos.

\section{REFERÊNCIAS BIBLIOGRÁFICAS}

1. BEN-ZVI, R.; EYLON, B.S.; SILBERSTEIN, J., Students' visualization of a chemical reaction. Education in Chemistry, v. 24, p. 117-120, 1987. 
2. BEN-ZVI, R.; EYLON, B.S.; SILBERSTEIN, J. Theories, principles and laws. Education in Chemistry, v. 25, p. 89-92, 1988.

3. BRASIL. Ministério da Educação - Secretaria de Educação Média e Tecnológica. PCN's Médio - Parte III: Ciências da Natureza, Matemática e suas Tecnologias - Brasília: MEC/SEMTEC, 1996.

4. BRASII. Ministério da Educação - Secretaria de Educação Básica. Orientações Curriculares para o Ensino Médio. Brasília: MEC/SEB, 2006.

5. FACH, M; BOER, T. de; PARCHAMANN, I, Results of an interview study as basis for the development of stepped supporting tools for stoichiometric problems. Chemistry Education Research and Practice, v. 8, n. 1, p. 13-31, 2007.

6. GABEL, D.L.; SAMUEL, K.V.; HUNN, D. Understanding the Particulate Nature of Matter, Journal of Chemical Education, v. 64, p. 695-697, 1987.

7. LOPES, A. C. Currículo e Epistemologia. Ijuí (RS): Editora Unijuí, 2007.

8. MACEDO, L. Os jogos e sua importância na escola. Cadernos de Pesquisa, v. 93, p. 5-11, 1995.

9. NAHUM, T. L.; MAMLOK-NAAMAN, R.; HOFSTEIN, A.; KRAJCIK, J. Developing a New Teaching Approach for the Chemical Bonding Concept Aligned with Current Scientific and Pedagogical Knowledge. Science Education. v. 91, p. 579-603, 2007.

10. NICOLL, G. A report of undergraduates' bonding misconceptions. International Journal of Science Education. v. 23, n. 7, p. 707-730, 2001.

11. PELLEGRINI, A. D. Perceptions and Functions of Play and Real Fighting in Early Adolescence. Child Development, v. 74, n. 5, p. 1522-1533, 2003.

12. PIAGET, J. A Epistemologia Genética. In. Os pensadores. São Paulo: Editora Abril Cultural, 1978.

13. ROCHA, J. R. C. da; CAVICHIOLLI, A. Uma Abordagem Alternativa para o Aprendizado dos Conceitos de Átomo, Molécula, Elemento Químico, Substância Simples e Substância Composta, nos Ensinos Fundamental e Médio, Química Nova na Escola, v. 21, n. 1, p. 29-33, 2005.

14. WU, H.-K.; KRAJCIK, J. S.; SOLOWAY, E. Promoting conceptual understanding of chemical representations: Students' use of a visualization tool in the classroom. Journal of Research in Science Teaching, v. 38, p. 821-842, 2001. 